\title{
Optimising electrochemical remediation for historic steel framed structures
}

\author{
P. Lambert \\ Mott MacDonald, Materials \& Corrosion Engineering, UK
}

\begin{abstract}
The problem of damage to historic steel framed structures as a result of corrosion is now widely recognised in Western Europe, America and Australia. Structures built in the late $19^{\text {th }}$ or early $20^{\text {th }}$ century are at greatest risk, together with earlier buildings that have received modifications or structural interventions during this period.

Traditional methods of repair are often too intrusive and too expensive to consider. As a consequence a number of important structures are at risk of incurring extensive damage to their stone and faience finishes that may require replacement with new, non-original elements.

Cathodic protection (CP) has been seen as a possible electrochemical solution to the problem of steel frame corrosion and has been in use in the UK and elsewhere for several years. In the absence of formal guidance and standards, most installations rely on the skill and experience of the designers and installers to ensure effective remediation.

To assist in the development of such guidelines, the Royal Society has supported a four year research programme into the use of CP on historic structures, carried out at the Centre for Infrastructure Management at Sheffield Hallam University.

This paper describes the completed study, its results and conclusions and shows how modelling of the processes has helped identify the key factors in the successful application of this technique to achieve maximum protection with minimum disruption to the original structure.
\end{abstract}

Keywords: steel framed structures, metallic corrosion, numerical modelling, cathodic protection. 


\section{Introduction}

The identification of "Regent Street Disease" in the late 1970's first highlighted the problems of steel frame corrosion occurring on the grand and often listed structures in the centres of many cities. This form of construction, first employed in Chicago and subsequently used in most major western cities in the first two decades of the $20^{\text {th }}$ century, has resulted in serious consequences with respect to serviceability, sustainability, safety and aesthetics.

Cathodic protection, originally developed by Humphry Davy [1] and later employed widely on buried and submerged structures, was first considered for reinforced concrete in the late 1950's. It was not until the development of improved anode systems based on catalysed titanium and titanium oxide in the early 1980's and the considerable advances in digital operating systems that it became a serious commercial solution.

The transfer to steel framed buildings was somewhat slower and it was not until 1997 that the first full structure, Gloucester Road Underground Station [2], was protected by such a system. Even now, with several sizeable installations in the UK and others appearing worldwide, there are no formal guidelines for the design, installation and operation of such systems. Most of the knowledge is based on empirical observation, lacks depth of understanding and is in the hands of a very small number of specialists.

The aim of the Royal Society funded research programme was to return to first principals in the evaluation of the corrosion processes involved in the disruption of structures incorporating steel frames and how it can be controlled through the use of cathodic protection. Numerical modelling of the cathodic protection currents was developed in parallel with practical studies employing sand to represent the electrolytic properties of masonry. From these models it has been possible to both better understand the processes occurring and develop optimised designs for the protection of such structures with minimal intervention.

\section{Corrosion processes in steel framed structures}

Steel framed masonry clad construction became popular around the turn of the $20^{\text {th }}$ century and many of the grand commercial and municipal buildings found in European city centres constructed between 1900 and 1940 employed this form of construction (see Figure 1). The steel frames were generally dependent upon the quality of their encapsulation to prevent corrosion. Often they would have a cement wash or bitumen emulsion coating but this was only intended to be a holding primer to prevent corrosion during transport.

Over the last 75 to 100 years, the protection has broken down and the steel has corroded, resulting in cracking and displacement of masonry as the high volume corrosion has filled up the gaps between the frame and the cladding, as shown in Figure 2. In extreme cases, the steel members have lost sufficient section to impair their structural capacity, requiring the inclusion of new or additional steel. In the presence of moisture and oxygen, steel and other simple ferrous alloys undergo corrosion resulting in a loss of metal and the formation of expansive corrosion products commonly referred to as rust. The rate and nature 


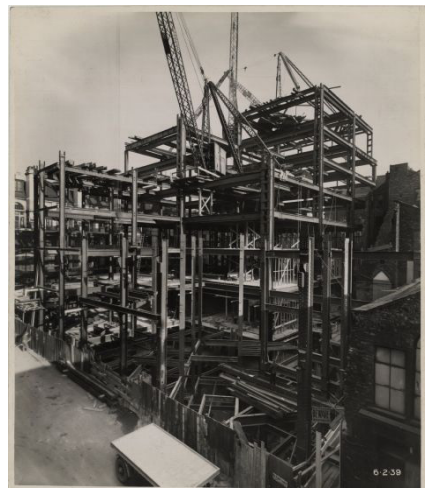

Figure 1: $\quad$ Steel frame construction circa 1939.

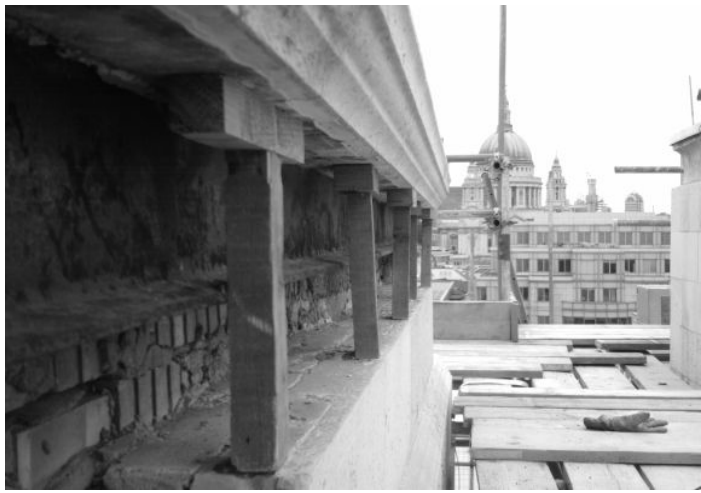

Figure 2: Corrosion of steel frame resulting in displacement of masonry cladding.

of the process depends on alloy composition, environmental factors, design and the presence of additional protection.

Aqueous corrosion requires two reactions to be sustained simultaneously. One reaction results in metallic iron being converted to iron ions with an associated release of electrons, this is the 'anodic' reaction. At the same time in an adjacent area, these electrons are combined with water to produce hydroxyl ions which protect the steel, this is the 'cathodic' reaction. Dissolved metal ions react with hydroxyl ions to form the familiar corrosion products and the anodic areas gradually lose section [3].

Traditional methods of repair require the displaced masonry to be removed and the corroded frame to be cleaned and recoated prior to reinstating the cladding. This is not only disruptive and expensive, but generally leaves large areas of corrosion where no displacement of the masonry has occurred untreated and the level of damage to the masonry will commonly require new material to be employed in the reconstruction, thereby undermining the authenticity of the structure.

Cathodic protection of such structures, introduced toward the end of the last century, has provided a technically feasible and commercially viable alternative to the repair and maintenance of such structures and continues to gain favour in such applications. In simple terms, cathodic protection works by making all the steel to be protected a cathodic with respect to a system of installed anodes. These can be self-powered galvanic or, more commonly inert anodes powered by a low voltage DC supply. Details of such systems have been described in detail elsewhere [4].

\section{Sand box studies}

The experimental and numerical studies on cathodic protection systems for steel framed masonry structures were initially conducted employing sand as a model 


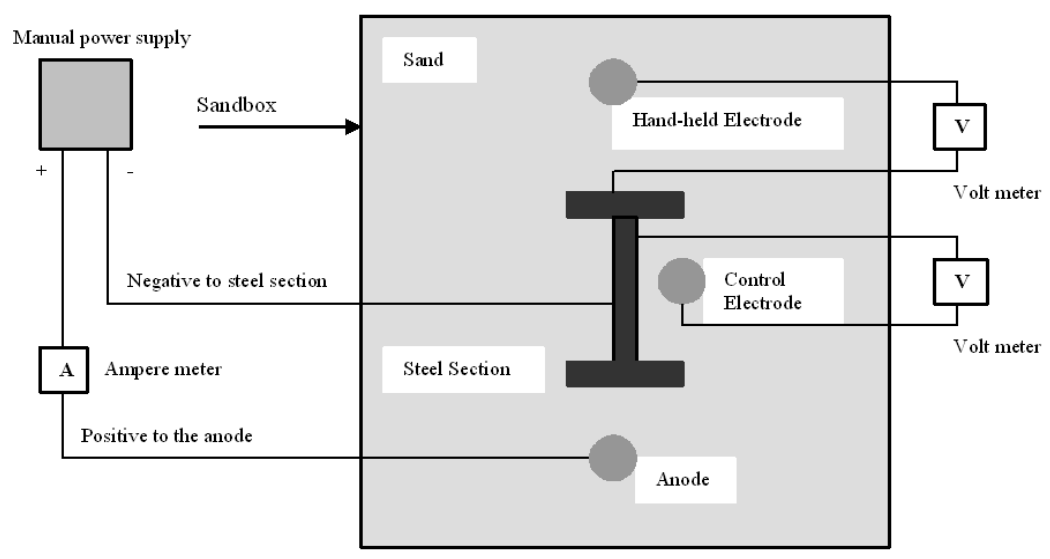

Figure 3: General arrangement of sand box tests.

for masonry [5]. The arrangement for such tests is shown in Figure 3 and an example of a sand box test representing a stanchion is shown in Figure 4. Similar tests were carried out with the steel section laid horizontally to represent a beam. The sand, dampened with tap water, represents a homogeneous electrolyte with a consistent resistivity.

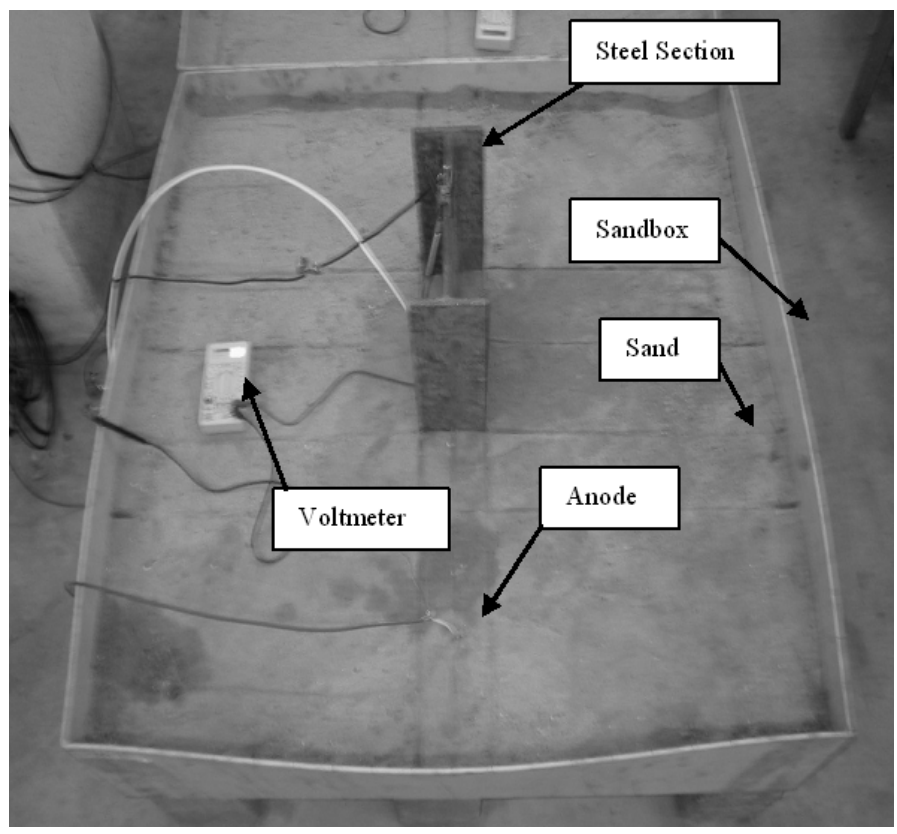

Figure 4: Sand box test representing a stanchion. 


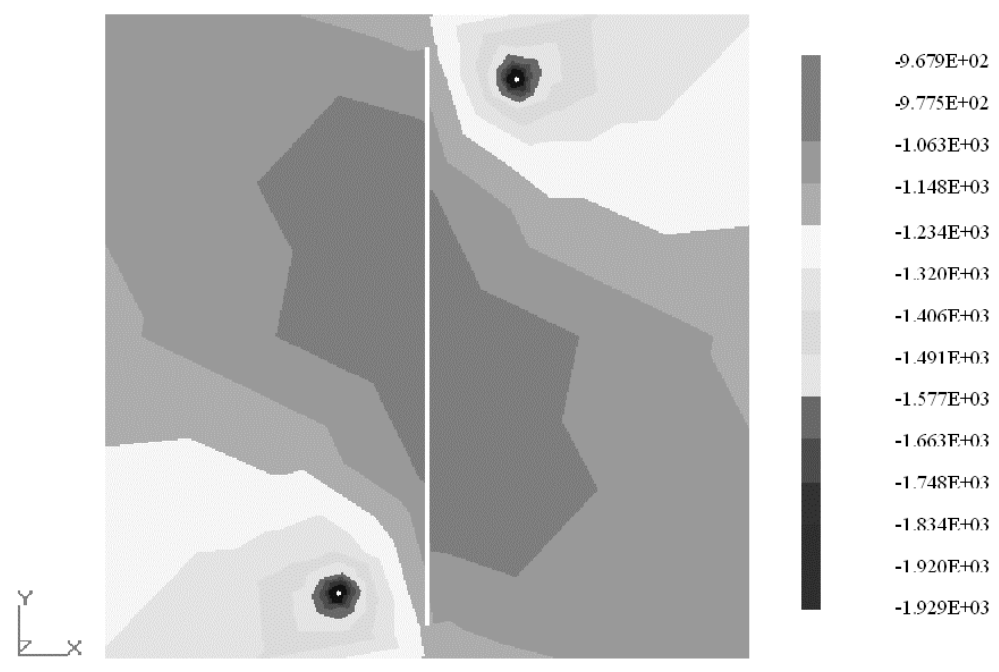

Figure 5: Potential distribution for steel beam (white line) polarised by two anodes (white dots).

This approach allowed the distribution of protective potential and current to be studied on the relatively complex geometry of the steel sections. Figure 5 shows the potential distribution for a beam provided by two anodes (indicated by the white dots). All potentials are in millivolts versus a copper/copper sulphate electrode (CSE). From this stage of the study it was possible to make the following conclusions.

- There is a significant variation of protective potential and current density in different regions of the steel surface. This variation is related not only to the resistivity of electrolyte and the anode locations but also to the geometry of the steel section.

- The distribution of CP potential and current density is directly related to the resistivity of the electrolyte. Under the same applied current density and anode location, the distribution of the protective potential and current density is more uniform in a low resistivity electrolyte. A higher resistivity electrolyte results in a lower protective current density on the steel.

- The anode position has a significant effect on the distribution of CP potential and current density. The potential and current density distributions along the surface of steel section become more uniform as the anode distance from the steel increases.

\section{$4 \quad$ Numerical modelling}

Having established a practical method of representing steel in masonry under the influence of cathodic protection, it was necessary to review the various 


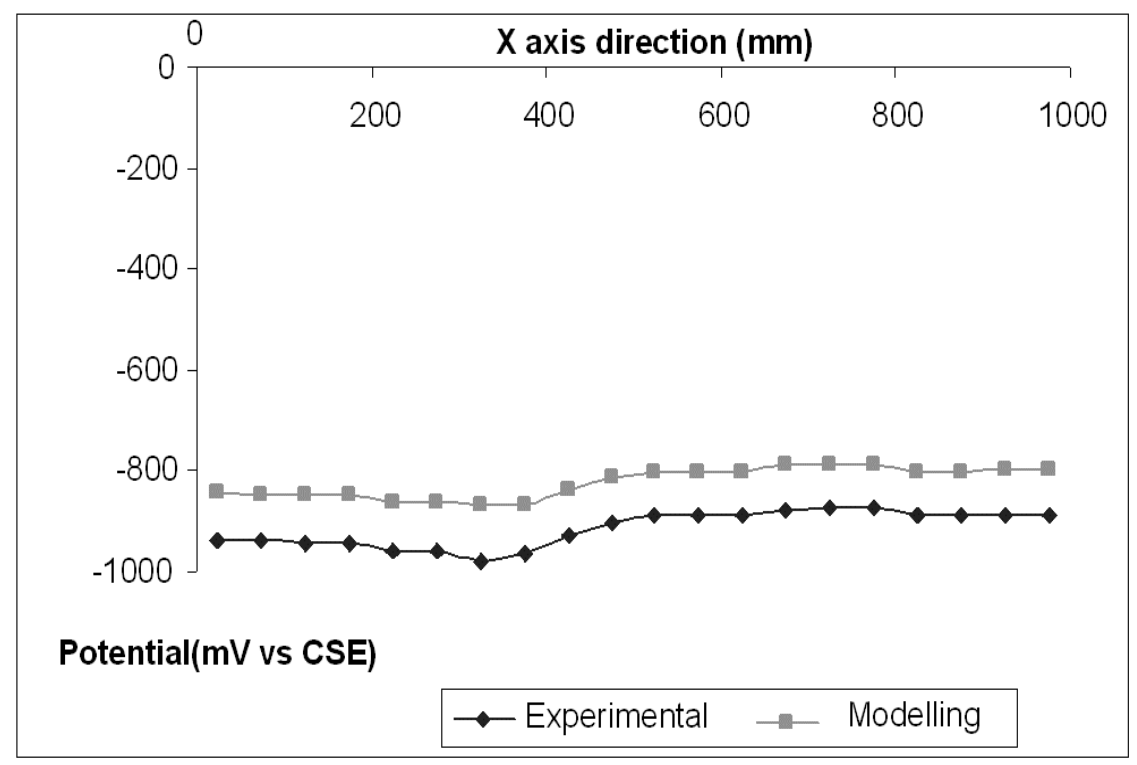

Figure 6: Comparison of experimental and modelled potential line scan for steel beam in sand.

numerical methods available for modelling the $\mathrm{CP}$ protection currents and resulting potentials. The finite element method and boundary element method have been used to analyse the protective current and potential distribution of cathodically protected reinforced concrete structures and offshore or marine structures respectively [6, 7]. More recently, the latter has been introduced to analyse cathodic protection systems for steel-framed masonry structures [8].

By employing the boundary element method, it has been possible to model the theoretical distribution of potential and current for a number of typical configurations and compare the results with those measured in the sand box experiments. There is generally good agreement, as shown in the comparison of line scan results shown in Figure 6.

As can be seen, the results follow the same trend although the experimental results are typically $100 \mathrm{mV}$ more negative. The cause for this variation could be related to a number of reasons. For example, in boundary element modelling, the sand resistivity is assumed to be uniform whereas in reality, the sand resistivity will not be precisely the same in each experiment and there will be some variation between different areas of the sandbox. It is also possible that the formation of the passive film on the steel section, the desired consequence of applying $\mathrm{CP}$, does not occur evenly leading to some variability.

Despite these errors the boundary element method provides sufficiently accurate results to produce potential and current distribution maps for the surface of buried steel elements and identify areas of excessive or inadequate polarisation, as shown in Figure 7. 


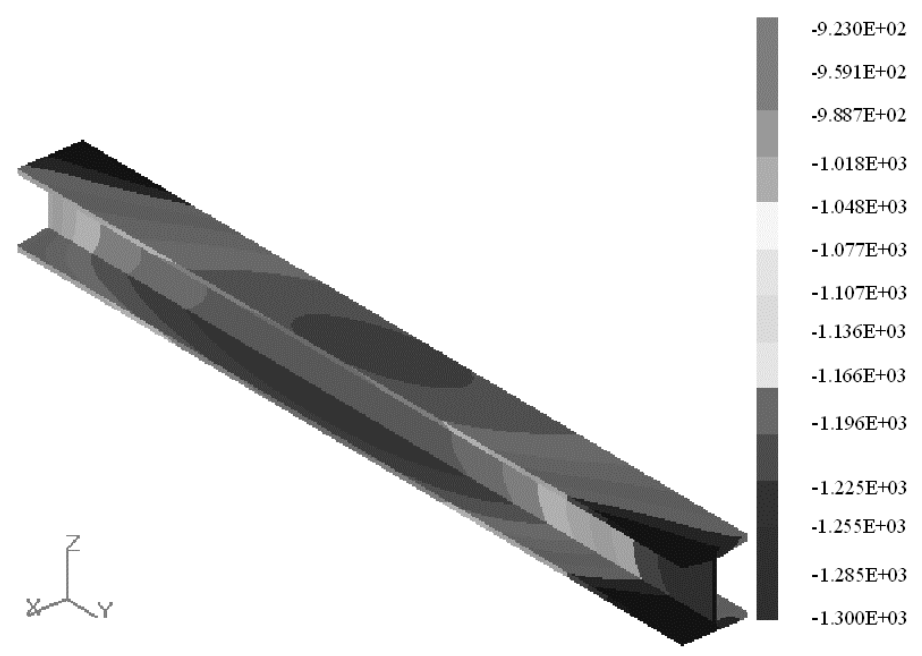

Figure 7: Potential distribution on the surface of a steel beam subject to cathodic protection, as modelled by the boundary element method.

\section{Stray current effects}

Steel-framed masonry buildings contain a variety of metallic elements. In addition to the frame itself, metal window frames, drain pipes and fixings such as wall ties and clamps are commonly encountered. Generally electrical continuity between structural members is rarely a problem [9] since the structural connections are typically bolted or riveted. However, other elements are more likely to be electrically discontinuous and this must be taken into account when designing a CP systems. Failure to ensure the electrical continuity of all metallic elements could result in stray current interactions between the various elements of the structure, resulting in accelerated corrosion of the discontinuous items.

By employing the boundary element method, it has been possible to model the effect of discontinuous steel on stray current corrosion and the results have been compared with weight loss measurements from sand box tests, as shown in Figure 8 . The model predicts the steel between the anode and the steel section will pick up current on the face nearest the anode and release current on the face nearest the steel section, the latter resulting in a loss of metal. For the other bar, while there is some pick up, there is relatively little loss and consequently little or no corrosion [10].

Estimated weight losses based on the modelled currents compared well with actual weight loss measurements obtained from the bars, demonstrating the validity of the boundary element method for assessing the effects of stray current on discontinuous metallic items. 


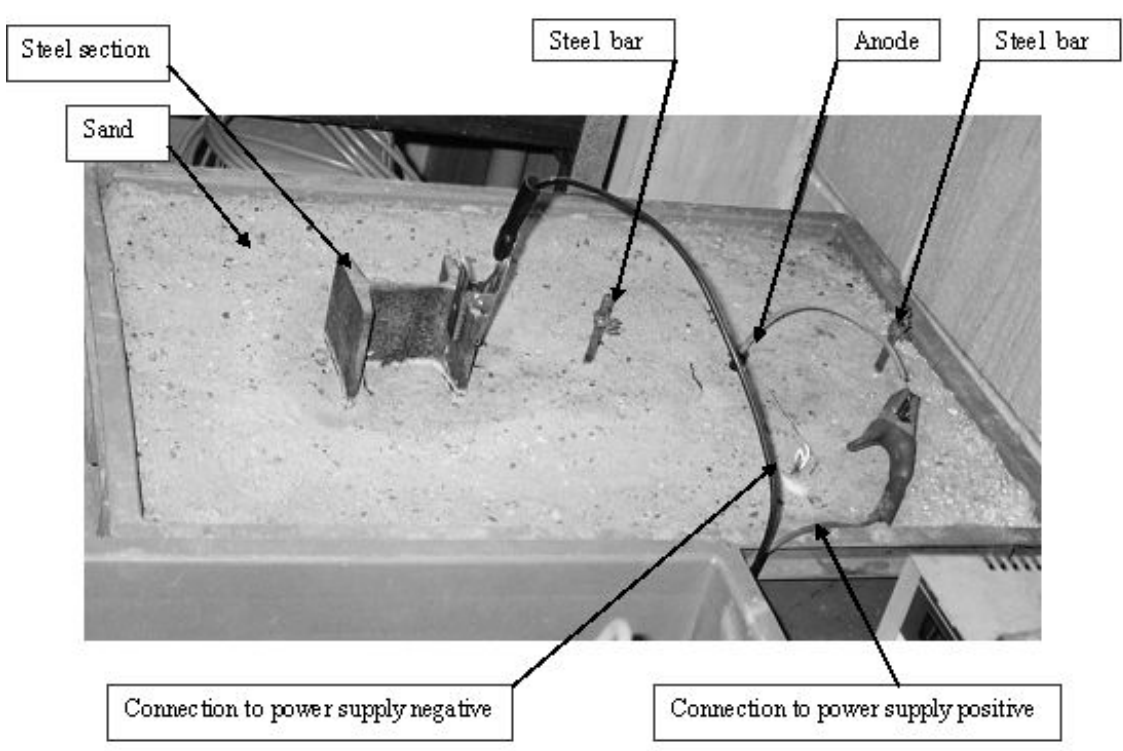

Figure 8: Sand box test to assess stray current effects.

\section{Design implications}

Having demonstrated the adequacy of the model, it has subsequently been employed to assist in the detailed design of cathodic protection systems for historically significant steel framed structures (see Figure 9).

The model can assist in the optimisation of anode locations in two ways. Firstly, it can help identify the best locations for anodes so as to achieve full protection from the least number of anodes, this in turn reduces the number of holes that have to be made in the structure and saves both money and resources.

The second way in which the model can be of benefit is where there are preferred locations for anodes, for example at joints, and the adequacy of the protection afforded by these anode locations can be assessed prior to installation.

\section{Future work}

The model generated from this work also has potential as a development tool for improving the performance of $\mathrm{CP}$ systems and overcoming a number of the practical problems presently encountered.

The ability of the model to accommodate stray current effects should make it possible to improve the present methods of dealing with discontinuous metallic items, such as clamps and wall ties. It should also be possible to develop more 


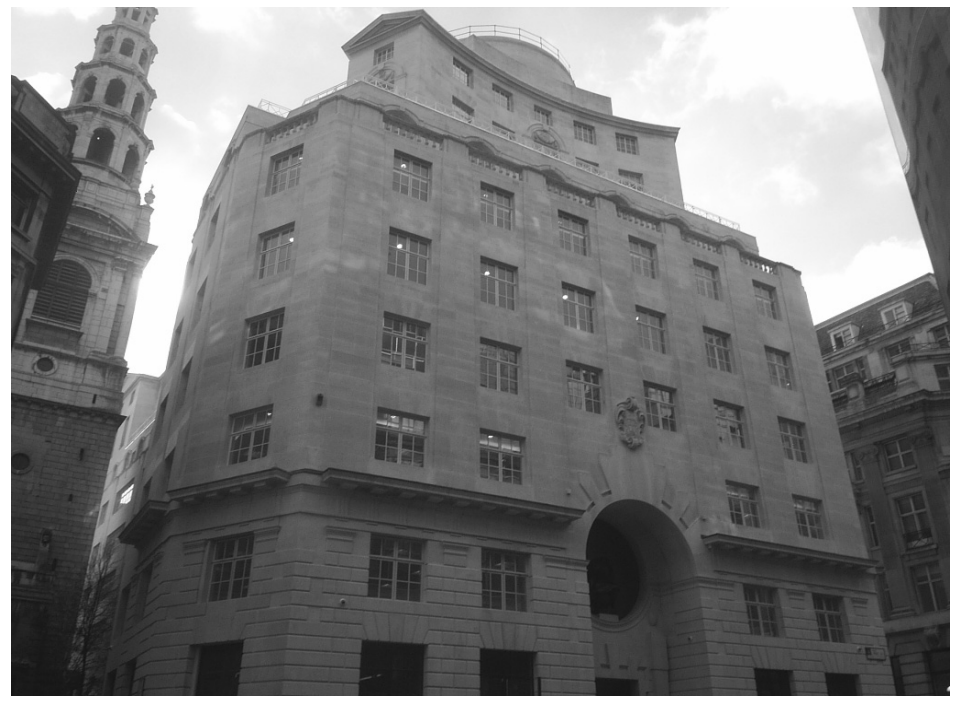

Figure 9: Recently completed CP installation to a heritage steel framed building.

efficient systems with savings in both the cost of installation and the long term running costs.

One area considered worthy of further investigation with the assistance of the model is the employment of pulsed power supplies which have only previously been employed in oil and gas applications [11].

Such systems, if found to be workable, could increase the efficiency of the CP installations and reduce both the number of anodes required and the extent of stray current effects on discontinuous items to provide more practical and sustainable solutions for the preservation of steel framed heritage structures.

\section{Conclusions}

By employing the sand box technique, an approach more commonly used in the study of pipeline $\mathrm{CP}$, it has been possible to verify the validity of numerical modelling based on the boundary element method for optimising electrochemical remediation systems for historic steel framed structures.

Laboratory tests on simple masonry encased steel samples have further confirmed the accuracy of the method in predicting the distribution of cathodic protection on actual structures. Such modelling has subsequently been employed in the design of $\mathrm{CP}$ systems for major heritage structures and has proved valuable in allowing the location and number of anodes to be optimised, thereby reducing both the costs and level of damage to the original building fabric.

It is hoped that further studies on pulsed power supplies will result in simpler systems and permit more widespread application of this remediation technique. 


\section{Acknowledgements}

The role of the Royal Society, Sheffield Hallam University and Mott MacDonald in the support of this study is gratefully acknowledged together with the invaluable contribution to the experimental and numerical modelling work made by $\mathrm{Dr} \mathrm{Yu}-\mathrm{You} \mathrm{Wu}$.

This paper is dedicated to the late Bob Chatburn of Mott MacDonald in recognition of a lifetime of commitment to excellence in steel design.

\section{References}

[1] Davy H, 'On the corrosion of copper sheeting by seawater, and on methods of preventing this effect, and on their application to ships of war and other ships'. Proceedings of the Royal Society, 114, pp.151-246, 1824 and 115, pp.328-346, 1825.

[2] Evans B, 'Electric Refurbishment', The Architects' Journal, pp 59-61, November 1997.

[3] Lambert, P, 'Corrosion mechanisms - an introduction to aqueous corrosion', Corrosion Prevention Association, Technical Note No.5, 2001.

[4] Lambert P \& Atkins C P, 'Cathodic protection of historic steel framed buildings', Structural Studies, Repairs and Maintenance of Heritage Architecture XI, Malta, pp 491-500, 2005.

[5] Lambert P, Mangat P S, O'Flaherty FJ \& Wu Y-Y, 'Cathodic protection of steel framed masonry structures - experimental and numerical studies' Materials \& Structures, RILEM, 2007 (in press).

[6] Hassanein A M, Glass G K \& Buenfeld N R, 'Potential current distribution in reinforced concrete cathodic protection systems', Cement \& Concrete Composite, 24, pp.159-167, 2002.

[7] Adey R A, Niku S M, Brebbia C A \& Finnegan J, 'Computer aided design of cathodic protection', Boundary Element Methods VII, Villa Olmo, Lake Como, Italy, 1985.

[8] Lambert P \& Wu Y-Y, 'Electrochemical methods for the preservation of masonry clad structural frames', Maritime Heritage and Modern Ports, Proceedings of the Second International Conference on Maritime Heritage, Barcelona, pp 219-228, 2005.

[9] Atkins C P, Lambert P \& Coull Z L, 'Cathodic protection of steel framed heritage structures", $9^{\text {th }}$ International Conference on Durability of Building Materials and Components, Brisbane Convention \& Exhibition Centre, Australia, 11pp, 2002.

[10] Wu Y-Y 'Cathodic protection of steel framed masonry structures', $\mathrm{PhD}$ Thesis, Sheffield Hallam University, UK, 2005.

[11] Bich N N \& Bauman J, 'Pulsed current cathodic protection of well casings', Materials Performance, Vol. 34, No. 4, pp 17-21, 1995. 